\title{
Performance Analysis and Discussion on the Thermoelectric Element Footprint for PV-TE Maximum Power Generation
}

\author{
GUIQIANG LI, ${ }^{1,5}$ XUDONG ZHAO, ${ }^{1,6}$ YI JIN, ${ }^{2}$ XIAO CHEN, ${ }^{3}$ JIE JI, ${ }^{4}$ \\ and SAMSON SHITTU ${ }^{1}$
}

\begin{abstract}
1.-School of Engineering, University of Hull, Hull HU6 7RX, UK. 2.-Department of Precision Machinery and Precision Instrumentation, University of Science and Technology of China, Hefei, Anhui, China. 3.-State Key Laboratory of Fire Science, University of Science and Technology of China, 96 Jinzhai Road, Hefei 230026, China. 4.-Department of Thermal Science and Energy Engineering, University of Science and Technology of China, 96 Jinzhai Road, Hefei 230026, China. 5.—e-mail: Guiqiang.Li@hull.ac.uk. 6.—e-mail: Xudong.Zhao@hull.ac.uk
\end{abstract}

Geometrical optimisation is a valuable way to improve the efficiency of a thermoelectric element (TE). In a hybrid photovoltaic-thermoelectric (PV-TE) system, the photovoltaic (PV) and thermoelectric (TE) components have a relatively complex relationship; their individual effects mean that geometrical optimisation of the TE element alone may not be sufficient to optimize the entire PV-TE hybrid system. In this paper, we introduce a parametric optimisation of the geometry of the thermoelectric element footprint for a PV-TE system. A unicouple TE model was built for the PV-TE using the finite element method and temperature-dependent thermoelectric material properties. Two types of PV cells were investigated in this paper and the performance of PV-TE with different lengths of TE elements and different footprint areas was analysed. The outcome showed that no matter the TE element's length and the footprint areas, the maximum power output occurs when $A_{n} / A_{p}=1$. This finding is useful, as it provides a reference whenever PV-TE optimisation is investigated.

Key words: PV-TE, footprint, uni-couple, geometry, finite element method

\section{List of symbols}

$A_{c} \quad$ Area of the solar cell $\left(\mathrm{m}^{2}\right)$

$A_{n} \quad$ Area of the $n$-type of TE element $\left(\mathrm{m}^{2}\right)$

$A_{p} \quad$ Area of the $p$-type of TE element $\left(\mathrm{m}^{2}\right)$

$C \quad$ Concentration ratio

$C_{p} \quad$ Heat capacity at 1 atmosphere $\left(\mathrm{J} \mathrm{kg}^{-1} \mathrm{~K}^{-1}\right)$

$E_{\mathrm{PV}} \quad$ Power output of the PV cell per square meter

$\left(\mathrm{W} \mathrm{m}^{-2}\right)$

$G \quad$ Solar irradiance $\left(\mathrm{W} \mathrm{m}^{-2}\right)$

$h \quad$ Convection heat transfer coefficient $\left(\mathrm{W} \mathrm{m}{ }^{-2} \mathrm{~K}^{-1}\right.$ )

$k \quad$ Thermal conductivity $\left(\mathrm{W} \mathrm{m}^{-1} \mathrm{~K}^{-1}\right)$

$l_{n} \quad$ Length of the $n$-type of TE element (m)

$l_{p} \quad$ Length of the $p$-type of TE element (m)

$P \quad$ Power output of the PV/TE system (W)

$P_{\mathrm{PV}} \quad$ Electricity generated by $\mathrm{PV}$ cell (W)
$P_{\mathrm{TE}} \quad$ Electricity generated by TEG (W)

$T$ Temperature (K)

$T_{\mathrm{amb}} \quad$ Temperature of the ambient (K)

$u_{\text {wind }}$ Wind velocity $\left(\mathrm{m} \mathrm{s}^{-1}\right)$

\section{Greek symbols}

$\alpha_{c} \quad$ Absorptivity of PV cell

$\varphi \quad$ Solar cell temperature coefficient $\left(\mathrm{K}^{-1}\right)$

$\rho$ Density $\left(\mathrm{kg} \mathrm{m}^{-3}\right)$

$\eta \quad$ Efficiency of the PV/TE system

$\eta_{c} \quad$ Efficiency of the solar cell at standard condition

$\varepsilon \quad$ Emissivity

$\sigma_{b} \quad$ Stefan-Boltzmann's constant $\left(=5.67 \times 10^{-8} \mathrm{~W} \mathrm{~m}^{-2} \mathrm{~K}^{-4}\right)$

\section{INTRODUCTION}

Some of the most encouraging renewable energy sources are thermoelectric (TE) devices, because 
they can convert heat flux into electricity directly via the Seebeck effect. ${ }^{1}$ Some benefits of thermoelectric devices include noiseless operation, small weight, no moving parts (which increases the system lifetime), increased reliability and significantly reduced maintenance requirements. ${ }^{2,3}$

Generally speaking, the two ways to enhance the performance of $\mathrm{TE}$ devices ${ }^{4}$ are improving the thermoelectric material characteristics or optimising the existing thermoelectric devices. Specifically, the optimisation of TE element geometry has been the subject of increased research. Sahin and Yilbas ${ }^{5}$ investigated the influence of leg geometry on the performance of thermoelectric devices and found that the shape parameter positively affects the efficiency but negatively affects the power output. Borcuch et al. ${ }^{6}$ presented the influence of fin geometry design in hot-side heat exchangers, upon the operational parameters of a thermoelectric generator. Wang et al. ${ }^{7}$ investigated the design of heat sink geometry, including fin spacing and length, with two-stage optimisation. Yilbas and $\mathrm{Ali}^{8}$ introduced the dimensionless tapering parameter and analysed its effect on the first and second law efficiencies under various operating conditions. Jang and Tsai ${ }^{9}$ optimised thermoelectric module spacing and spreader thickness using a simplified conjugate-gradient method. Shen et al. ${ }^{10}$ theoretically analysed the performance of the annular thermoelectric couple. Lamba and Kaushik ${ }^{11}$ studied the influence of the Thomson effect and leg geometry configuration on the performance of a thermoelectric generator (TEG). Ali et al. ${ }^{12}$ performed the thermodynamic analysis of a TEG considering the geometric configuration of the device pins, and they found the thermal efficiency of the generator can be enhanced by increasing the dimensionless geometric parameter. Lavric performed a 1-dimensional thermal analysis of thermoelectric devices considering the geometry, and found that the electrical resistance is reduced by decreasing the leg length of the thermoelectric element. However, longer leg length would result in a greater temperature difference between the two ends of the legs. ${ }^{13}$ Rezania et al. ${ }^{14}$ optimized the footprint ratio of $n$-type and $p$-type TE elements, and results showed that when $A_{n} / A_{p}<1$, maximum power generation occurs.

Combining photovoltaic (PV) and thermoelectric (TE) components is a good way to take full advantage of the wider solar spectrum to produce electricity. ${ }^{15}$ The PV can absorb part of the incident solar energy to produce electricity directly, then the remaining solar energy can be converted as the thermal energy passes through the $\mathrm{TE}$, producing more electricity. Zhou et al. ${ }^{16}$ developed the multiphysics coupling mathematic model of the PV-TE hybrid system. Teffah and Zhang ${ }^{17}$ performed both the modelling and experimental research on hybrid PV-TE systems for highly concentrated conversion of solar energy.
Hashim et al. ${ }^{18}$ developed a model for optimising the geometry of thermoelectric devices in a hybrid PV-TE system, and argued that in practice, there is a trade-off between achieving large output power and using reduced thermoelectric material whenever an optimised geometry is desired. The physical size of the TEG in a hybrid system significantly influences the overall power output of the system because it determines the solar cell's operating temperature and the temperature difference across the TEG. Thus, previous conclusions regarding TE geometry optimisation may not be suitable for PV$\mathrm{TE}$ systems. For example, for the TE alone, maximum output power is achieved when the $n$-type and $p$-type footprints are dissymmetrical. ${ }^{14}$ However, it is still unknown if this would be applicable to the PV-TE because of the effects of the interaction between the PV and the TE components.

Only a few studies have focused on TE geometry optimisation, especially in the footprint area, to enhance hybrid PV-TE system performance. In addition, most recent research in PV-TE has been performed using temperature-independent thermoelectric materials. In actuality, thermoelectric material properties such as electrical resistance, thermal conductivity and the Seebeck coefficient are dependent on temperature. Thus, temperature-induced variations in thermoelectric material properties would result in different electrical voltage and temperature distributions within the system. ${ }^{19}$ Based on these facts, this paper focuses on optimizing the geometry of the TE footprint area in a PVTE system. Temperature-dependent TEG material properties are considered and FEM was used to simulate the system. This study will act as a valuable reference when the design of PV-TE geometry is undertaken.

\section{MODEL OUTLINE}

\section{Description of a Photovoltaic-Thermoelectric (PV-TE)}

The considered PV-TE uni-couple can be seen in Fig. 1. The surface of the PV cell is where solar irradiation is impinged and a significant portion of this solar irradiation is converted to electricity by the photovoltaic effect. The remaining solar energy is converted to thermal energy, which is partially transferred from the PV to the TE while the remainder is lost to the ambient environment. This process results in the a temperature difference across the TE element's hot and cold sides, and electricity is produced due to the thermoelectric effect.

\section{FEM Model}

The equations used to describe the behaviour of the PV-TE system in terms of heat transfer and current density are $^{20}$ : 


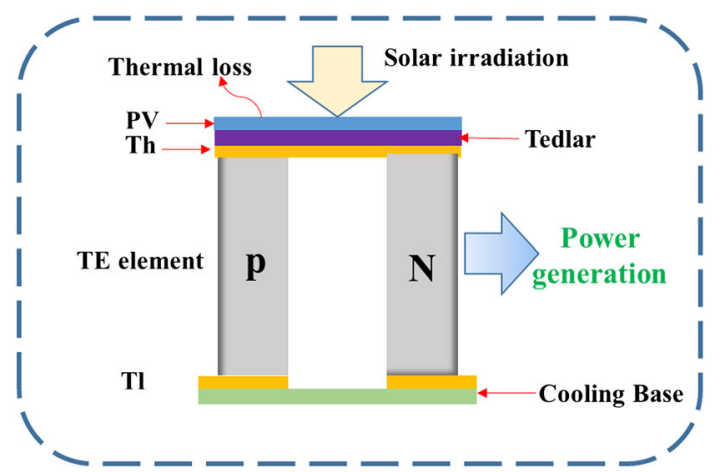

Fig. 1. Schematic diagram of a PV-TE uni-couple.

$$
\begin{gathered}
-k \nabla^{2} T+Q=\rho C_{p} \frac{\partial T}{\partial t} \\
\nabla \cdot\left(\xi \frac{\partial \overrightarrow{\boldsymbol{E}}}{\partial t}+\overrightarrow{\boldsymbol{J}}\right)=Q
\end{gathered}
$$

where $k$ is the thermal conductivity, $T$ is the temperature field, $Q$ is the internal volume heat source, $\rho$ is the density, $C_{p}$ is the heat capacity in standard conditions, $t$ is the time, $\xi$ is the electric permittivity, $\overrightarrow{\boldsymbol{E}}$ is the electrical field. $\overrightarrow{\boldsymbol{J}}$ is the current density which is produced by both the Joule effect and Seebeck effect. This is shown as

$$
\overrightarrow{\boldsymbol{J}}=\sigma(\overrightarrow{\boldsymbol{E}}-S \nabla T),
$$

where $\sigma$ is the electrical conductivity and $S$ is the Seebeck coefficient. $\vec{E}$ is the electric field and is obtained from the electric scalar potential $V$ as

$$
\overrightarrow{\boldsymbol{E}}=-\nabla V \text {. }
$$

The above differential Eqs. 1 and 2 can be transformed into finite element equations by approximating the unknown physical field variables, temperature $T$ and electric potential $V$. Temperature and electric potential can be interpolated using the functions, ${ }^{21}$

$$
\begin{gathered}
T=[N]\left\{T_{e}\right\} \\
V=[N]\left\{V_{e}\right\},
\end{gathered}
$$

where $V_{e}$ is the vector of the nodal electrical potential, $T_{e}$ is the vector of the nodal temperature, and $N$ is the element shape function.

The FEM model is described by the boundary conditions that are applied to the upper surface of the PV cell. The equation for the external heat flux is given as;

$$
q_{0}=C G \alpha_{c} A_{c}-E_{p v} A_{c}
$$

where $q_{0}$ is the external heat flux, $C$ is the concentration ratio of the solar radiation, $G$ is the solar radiation. $\alpha_{c}$ is the absorptivity of the PV cell, $A_{c}$ is the area of the PV. $E_{\mathrm{pv}}$ is the power output of the PV cell per square meter, which is given as;

$$
E_{\mathrm{pv}}=C G \eta_{c}\left[1-\varphi_{c}\left(T_{c}-298\right)\right],
$$

where $\eta_{c}$ is the standard PV efficiency at $25^{\circ} \mathrm{C}, \varphi_{c}$ is the solar cell temperature coefficient and $T_{c}$ is the PV temperature.

Due to the temperature difference between the upper surface of the PV and the ambient surroundings, the heat convection is given as

$$
q_{1}=h_{\text {air }} A_{c}\left(T_{\text {air }}-T_{c}\right),
$$

where $h_{\text {air }}$ is the convective heat transfer coefficient. The surface radiation heat transfer is written as

$$
q_{2}=\varepsilon \sigma_{b}\left(T_{\mathrm{amb}}^{4}-T_{c}^{4}\right) A_{c},
$$

where $T_{\mathrm{amb}}=0.0552 T_{\mathrm{air}}^{1.5}, \varepsilon$ is the emissivity of the $\mathrm{PV}$ and $\sigma$ is the Stefan-Boltzmann constant.

The last boundary condition is applied at the cold side. The cold side of the system, which is at the bottom, is placed in ice water to maintain a constant temperature of $273 \mathrm{~K}$. The equation for this condition is given as

$$
T_{l}=273 K \text {. }
$$

The TE uni-couple open circuit voltage and short circuit voltage are given as

$$
\begin{aligned}
& v_{\mathrm{oc}}=\bar{\alpha} \Delta \mathrm{T} \\
& I_{\mathrm{sc}}=\frac{v_{\mathrm{oc}}}{R} .
\end{aligned}
$$

The uni-couple average Seebeck coefficient is given as

$$
\bar{\alpha}=\frac{1}{T_{h}-T_{l}} \int_{T_{c}}^{T_{h}}\left(\alpha_{p}-\alpha_{n}\right) d T .
$$

The internal resistance of the uni-couple can be expressed as

$$
R=R_{n}+R_{p}=\left[\left(\sigma_{n} \frac{A_{n}}{H_{n}}\right)^{-1}+\left(\sigma_{p} \frac{A_{p}}{H_{p}}\right)^{-1}\right] .
$$

The output of the TE uni-couple element can be expressed as

$$
P_{\mathrm{TE}}=\frac{v_{\mathrm{oc}}^{2}}{R+R_{L}},
$$

where $R_{L}$ is the load resistance.

The sum of the PV and TEG respective power outputs give the total power output, and is given as

$$
P=P_{\mathrm{PV}}+P_{\mathrm{TE}}=E_{\mathrm{PV}} A_{c}+P_{\mathrm{TE}} .
$$

The PV-TE system efficiency is given as

$$
\eta=\frac{P}{C G A_{c}}=\frac{E_{\mathrm{PV}} A_{c}+P_{\mathrm{TE}}}{C G A_{c}} .
$$




\section{SIMULATION PROCEDURE AND INPUT PARAMETERS}

Simulation was performed to demonstrate the capability of the developed model for optimal PVTE design. Two different types of PV cells possessing two different temperature coefficients, and a series of TEGs with $n$ - and $p$-type footprint areas were chosen to investigate their effects on the power output. The PV details are shown in Table I, and the temperature-dependent TE material properties of $\mathrm{Bi}_{2} \mathrm{Te}_{3}$ used in the FEM simulation can be seen from Fig. 2. ${ }^{22}$ The different TE element lengths considered were $5 \mathrm{~mm}, 10 \mathrm{~mm}$, and $15 \mathrm{~mm}$. The $n$-type and $p$-type footprint total areas considered were $8 \mathrm{~mm}^{2}, 12.5 \mathrm{~mm}^{2}, 18 \mathrm{~mm}^{2}$, and $24.5 \mathrm{~mm}^{2}$.

COMSOL software was employed to present the FEM model's temperature and electrical fields. Accurate meshing of the PV-TE into small tetrahedrons was performed. Details of the PV-TE studied are given in Table II. We assumed that the cold side of the TE was maintained at a constant temperature of $273 \mathrm{~K}$. For each PV-TE, thirteen cases of the TE $n$-type and $p$-type area ratios were considered. These details, with the $n$-type and $p$-type footprint area ratios, are shown in Table III.

\section{RESULTS AND DISCUSSION}

The TEG uni-couple module temperature and voltage distributions are obtained by solving the FEM model. Temperature and voltage distributions in the PV-TE uni-couple using Cell_1 at $A_{n} / A_{p}=4.18$, $h=5 \mathrm{~mm}, A_{n}+A_{p}=18 \mathrm{~mm}^{2}$, are shown in Fig. 3 .

Compared to the common works on thermoelectricity in which the electrical resistivity, Seebeck coefficient and the thermal conductivity are taken as constants, here the electrical voltage and the temperature distributions are not all uniform. The $n$-type TE element has a lower temperature difference compared to the $p$-type TE element due to the $n$-type material's higher thermal conductivity.
Thus, across the uni-couple, the heat flux would increase as the footprint area of the $n$-type element increases. Consequently, if only the TEG is considered, the $n$-type element footprint area is needed to decrease the heat flux flowing across the uni-couple and also to get a high temperature difference across the TE. This would lead to more power output production as has been verified by Ref. 11. However, due to the effects caused by the combination of the $\mathrm{PV}$ and $\mathrm{TE},{ }^{23}$ the high temperature difference may cause low PV efficiency. Therefore, for a PV-TE, the TE-alone optimisation result that highest electrical power generation occurs when $A_{n} / A_{p}<1$ maybe not suitable.

The maximum PV-TE efficiency using Cell_1 can be seen from Fig. 4. The TE elements lengths considered are $5 \mathrm{~mm}, 10 \mathrm{~mm}$ and $15 \mathrm{~mm}$ as shown in Fig. $4 a, b$ and c, respectively. No matter what the length is, the maximum power outputs all occur when the areas of the $n$-type and $p$-type footprint are the same. Also, when the length is constant, no matter what the areas of the TE footprints are, the maximum power outputs all occur when the $n$-type and $p$-type footprint area are asymmetric. This implies that the maximum PV-TE power output occurs when $A_{n} / A_{p}=1$.

In addition, Fig. $4 \mathrm{a}$ shows that the maximum PVTE efficiency occurs at $A_{n}+A_{p}=8 \mathrm{~mm}^{2}$ when the TE element length is $5 \mathrm{~mm}$. The highest efficiency decreases as the $n$-type and $p$-type area sum increase. However, Fig. $4 \mathrm{c}$ shows that the minimum efficiency occurs at $A_{n}+A_{p}=8 \mathrm{~mm}^{2}$ when the TE element length is $15 \mathrm{~mm}$, and it increases as the $n$ type and $p$-type area sum increases.

The results show that at $A_{n} / A_{p}=1$, the PV-TE has the highest efficiency based on Cell_1.Values of PV-TE efficiencies corresponding to the length of TE elements with different uni-couple footprint areas are shown in Fig. 5. The highest efficiency with $A_{n}=A_{p}=2 \mathrm{~mm}^{2}$ is lower than that with a larger footprint area. But as the footprint area

Table I. Parameters used in FEM model

\begin{tabular}{|c|c|c|}
\hline Parameters & Symbol & Value \\
\hline Area of PV cell & $A_{c}$ & $10 \mathrm{~mm} \times 10 \mathrm{~mm}$ \\
\hline Thickness of PV cell & $H_{c}$ & $0.3 \mathrm{~mm}$ \\
\hline Thickness of tedlar & $H_{\text {ted }}$ & $0.175 \mathrm{~mm}$ \\
\hline Thickness of metal sheet & $H_{\mathrm{cu}}$ & $0.1 \mathrm{~mm}$ \\
\hline Absorptivity of PV & $\alpha_{c}$ & 0.9 \\
\hline Thermal conductivity of PV & $k_{c}$ & $148 \mathrm{~W} /(\mathrm{m} \mathrm{K})$ \\
\hline Thermal conductivity of tedlar & $k_{\text {ted }}$ & $0.2 \mathrm{~W} /(\mathrm{m} \mathrm{K})$ \\
\hline Thermal conductivity of metal copper & $k_{\mathrm{cu}}$ & $4.1 \mathrm{~W} /(\mathrm{m} \mathrm{K})$ \\
\hline Emissivity of PV & $\varepsilon$ & 0.8 \\
\hline Ambient temperature & $T_{\mathrm{amb}}$ & $298 \mathrm{~K}$ \\
\hline Wind velocity & $u_{w}$ & $1 \mathrm{~m} / \mathrm{s}$ \\
\hline Electrical conductivity of metal copper & $\mu_{\mathrm{cu}}$ & $58.1 \times 10^{6} \mathrm{~S} / \mathrm{m}$ \\
\hline Solar radiation & $G$ & $1000 \mathrm{~W} / \mathrm{m}^{2}$ \\
\hline Concentration ratio & $C$ & 5 \\
\hline
\end{tabular}


(a)

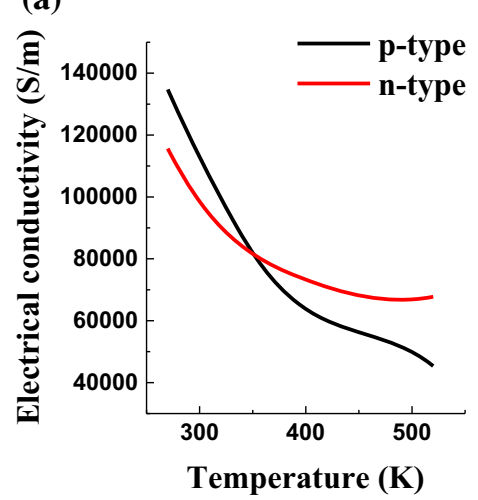

(b)

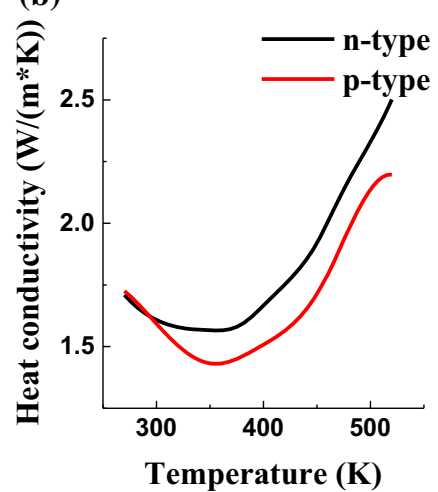

(c)

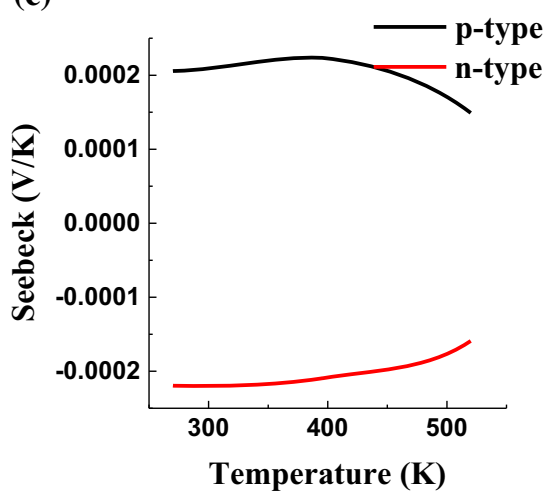

Fig. 2. Properties of the $\mathrm{Bi}_{2} \mathrm{Te}_{3} \mathrm{TE}$ materials: (a) electrical conductivity, (b) heat conductivity, and (c) Seebeck coefficient.

Table II. Two types of PV cells used in the study

\begin{tabular}{lccc}
\hline PV cells & Efficiency at standard condition (\%) & & ${\text { Temperature coefficient }\left(\mathbf{K}^{-\mathbf{1}}\right)}^{ }$ \\
\cline { 3 - 4 } Cell_1 & 10 & -0.001 \\
Cell_2 & 15 & -0.004 \\
\hline
\end{tabular}

Table III. Footprint dimensions of the TE elements with the area ratio of $n / p$ TEG elements

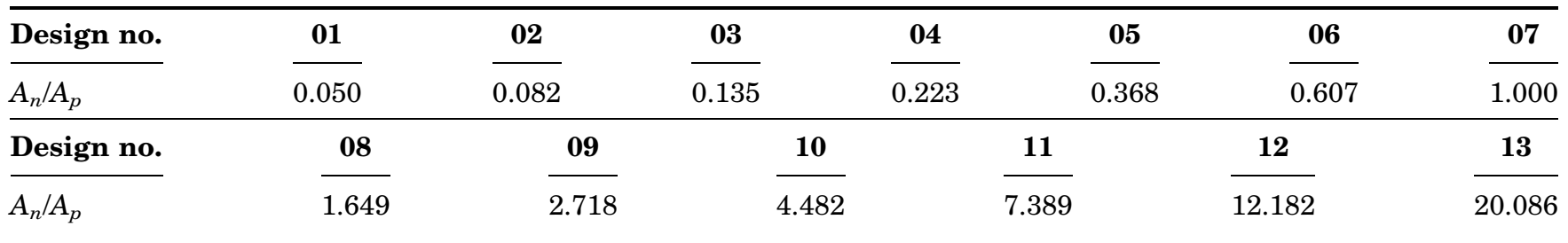

increases, the highest PV-TE efficiency occurs at the larger length of the TE element, and the curve of the efficiency has a tendency to go up and down with the increase of TE element length.

There is a tendency for PV-TE efficiency to go up and down with the same length of TE element when the footprint area increases, as shown in Fig. 6. The PV-TE with the short of TE element length has the maximum efficiency with the small footprint area. Longer TE elements have larger thermal resistance and electrical resistance, but the larger TE footprint area results in lower thermal resistance and electrical resistance, so we must find an optimal match between the footprint area and the length of TE element to achieve maximum output.

Considering Cell_2, Fig. 7 shows the relationship between the PV-TE efficiency and different $n$-type and $p$-type area ratios. Cell_2 has a larger temperature coefficient, so the $\mathrm{PV}-\mathrm{TE}$ has a strict limit such that the PV-TE efficiency should be higher than that of PV alone. It is clear that when the length of the TE element is $10 \mathrm{~mm}$ or $15 \mathrm{~mm}$, the efficiencies of PV-TE with the total footprint area of
$8 \mathrm{~mm}^{2}, 12.5 \mathrm{~mm}^{2}, 18 \mathrm{~mm}^{2}$, and $22.5 \mathrm{~mm}^{2}$ are all lower than the efficiency of PV alone. But whether the PV-TE efficiency is higher or lower, the maximum efficiencies of the PV-TE all occur when the $n$-type and $p$-type footprint areas are the same.

Based on Cell_2, when $A_{n} / A_{p}=1$, the PV-TE efficiency decreases as the length of the TE element decreases, as shown in Fig. 8, and when the footprint area is large, the efficiency decline is small as the length of the TE element increases. So the PVTE with the larger footprint area has the advantage because the PV-TE efficiency should be above 15.0\%. As shown in Fig. 9, the curve of PV-TE efficiency increases as the TE footprint area increases. With the same footprint area, a higher efficiency is observed with the shorter TE element length.

For the TE alone, the small footprint and long length of the TE element can lead to low thermal conductivity and high electrical resistance. Based on $A_{n} / A_{p}<1$, considering the economic factor, the geometrical optimisation usually needs tbee highly cost-effective. However, for the PV-TE, the total 

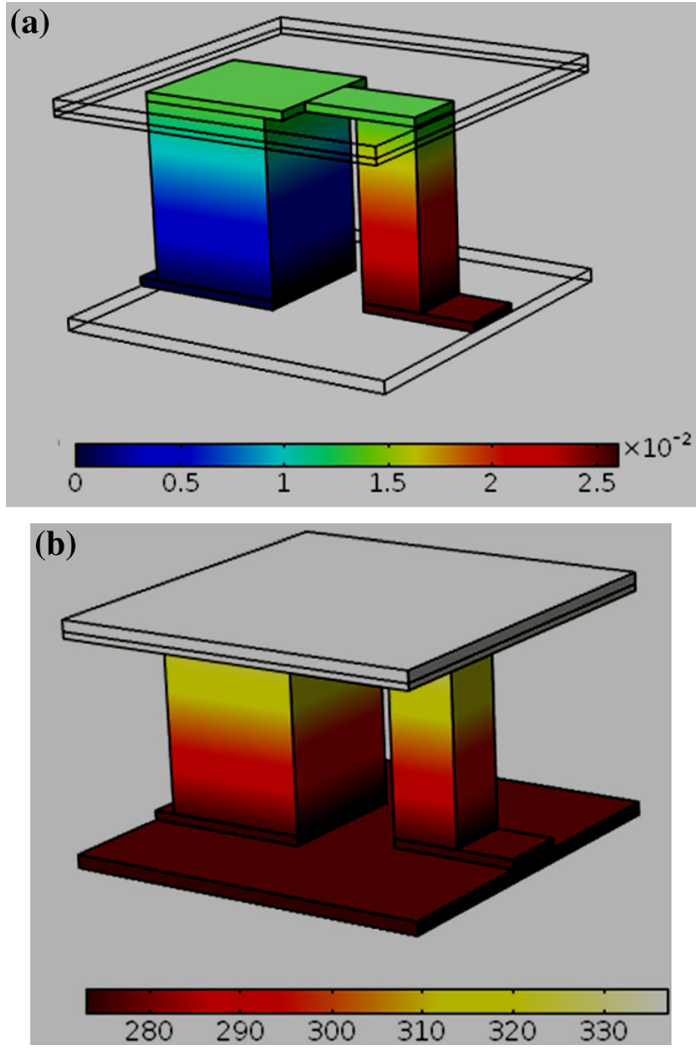

Fig. 3. (a) Schematic diagram generation of the electric voltage. (b) 3D temperature distribution of the PV-TE using PV cell Cell_1, $A_{n}$ $A_{p}=4.18, h=5 \mathrm{~mm}$, and $A_{n}+A_{p}=18 \mathrm{~mm}^{2}$.

efficiency is not just determined by the TE but also by the PV, and the PV and TE can also be affected by each other. High thermal resistance can enhance the efficiency of TE, however it weakens the efficiency of PV. Furthermore, the PV contributes more towards the highest power output of the PV-TE because the its electrical efficiency is high. But different types of solar cells have different characteristics. For Cell_1 with a small temperature coefficient, a high temperature can be reached for $\mathrm{TE}$, so the TE can be optimised in a large geometrical scope in which the total efficiency can be kept above $15.0 \%$. By contrast, Cell_2, which has a large temperature coefficient, the temperature that can enhance the efficiency of TE would significantly reduce the efficiency of $\mathrm{PV}$, and in many cases the PV-TE efficiency becomes lower than that of the PV. Thus, low temperature can maintain high efficiency for the PV, but would limit the power output of the TE.

This study has shown that the PV-TE hybrid system achieves its highest efficiency when the $n$ type and $p$-type footprint area ratio is symmetric, and this is different from that of a TE alone. ${ }^{24}$ For Cell_1, many of the PV-TE electrical efficiency results are higher than $10 \%$ because of the cell's low temperature coefficient. However, the highest efficiency of the PV-TE is still lower than $12.5 \%$, no
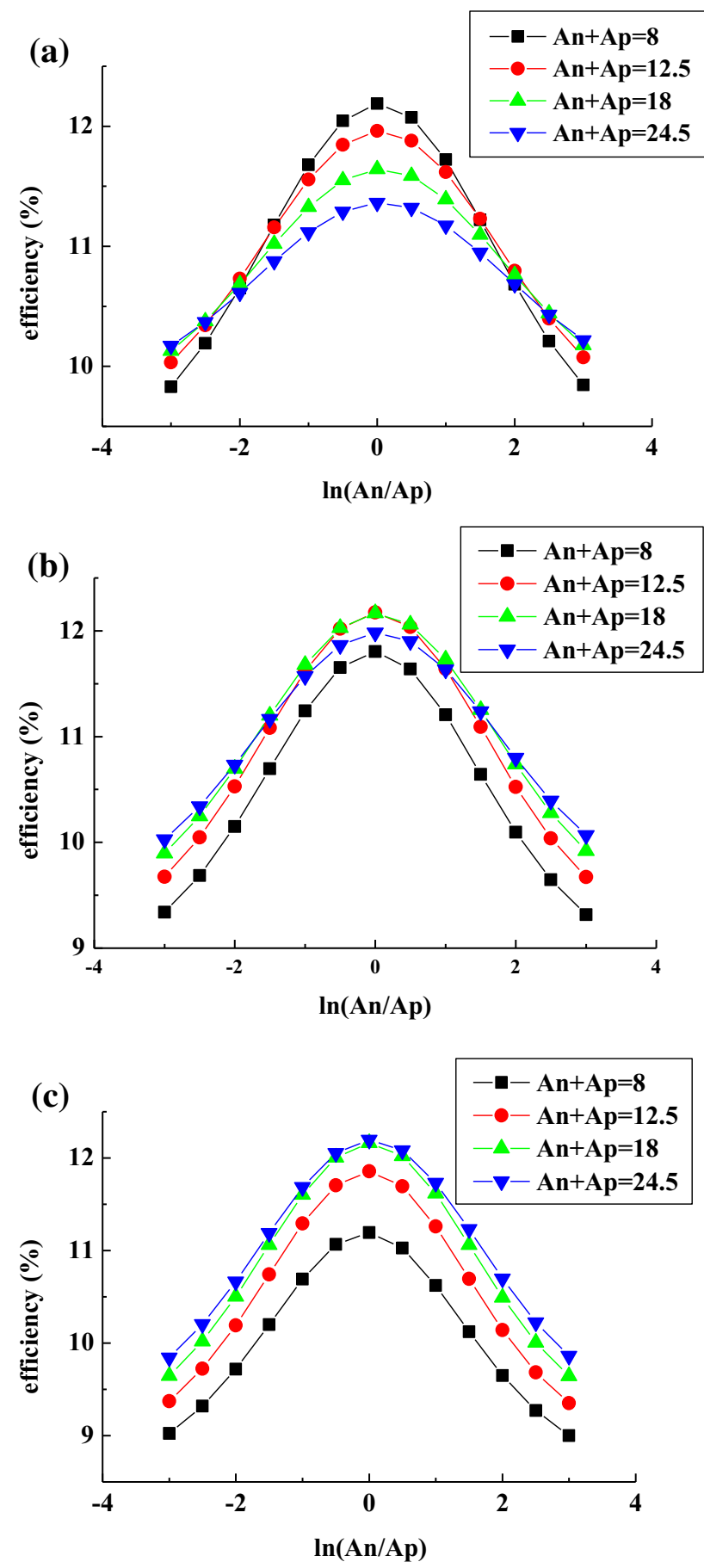

Fig. 4. Variation of the PV/TE efficiency with the area ratio between $n$-type and $p$-type using the PV cell Cell_1. The lengths of TE elements are (a) $5 \mathrm{~mm}$, (b) $10 \mathrm{~mm}$, and (c) $15 \mathrm{~mm}$.

matter the TE elements' $n$-type and $p$-type length and the area. Viewed from an economic perspective, using low values for the length and area of the $n$ type and $p$-type TE elements is good for integration with the PV. Furthermore, the economic factor can be considered during the optimisation of the PV-TE employing Cell_2. 


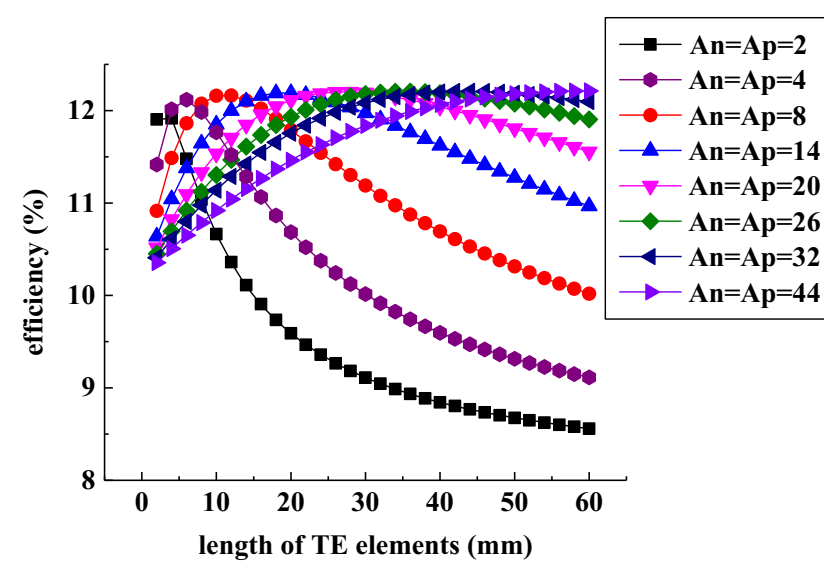

Fig. 5. Variation of the PV-TE efficiency with different length of TE elements based on Cell_1.

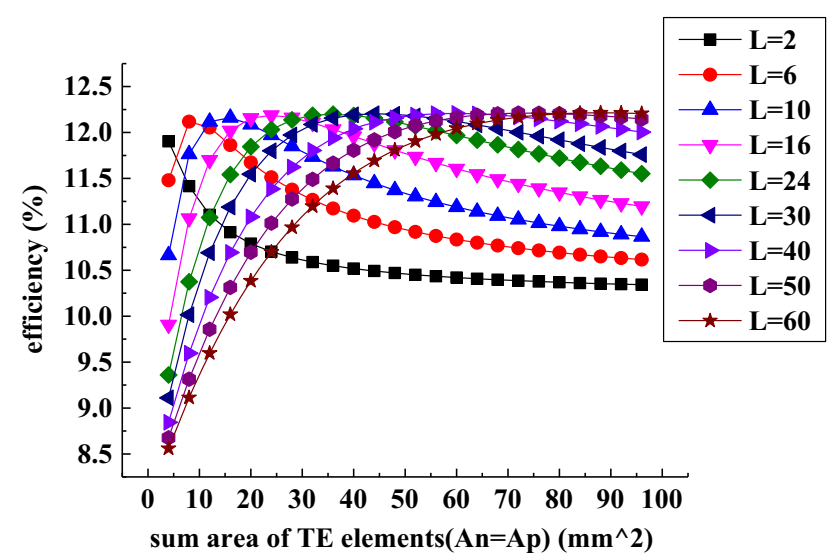

Fig. 6. Variation of the PV-TE efficiency with different footprint areas of TE elements based on Cell_1.

\section{CONCLUSIONS}

This study investigated the optimum footprint area for thermoelectric elements maximum power generation in a PV-TE hybrid system. Temperature-dependent TE material properties were considered. Thermoelectricity equations were solved employing the finite element method model. In the uni-couple, temperature and voltage distributions were also presented.

Results obtained indicated that the PV-TE system's highest power output occurs when $A_{n} / A_{p}=, 1$ and that this is different from that of the TE-only system in which highest power output occurs when $A_{n} / A_{p}<1$. The major contribution to PV-TE efficiency is from the PV, however, temperature has a negative effect on the PV and a positive effect on the TE. Thus, the higher PV performance limits the TE performance in the PV-TE hybrid. Different $n$ - and $p$-type areas may increase the temperature difference, which would lead to a decrease in the PV-TE efficiency. Therefore, similar $n$-type and $p$-type
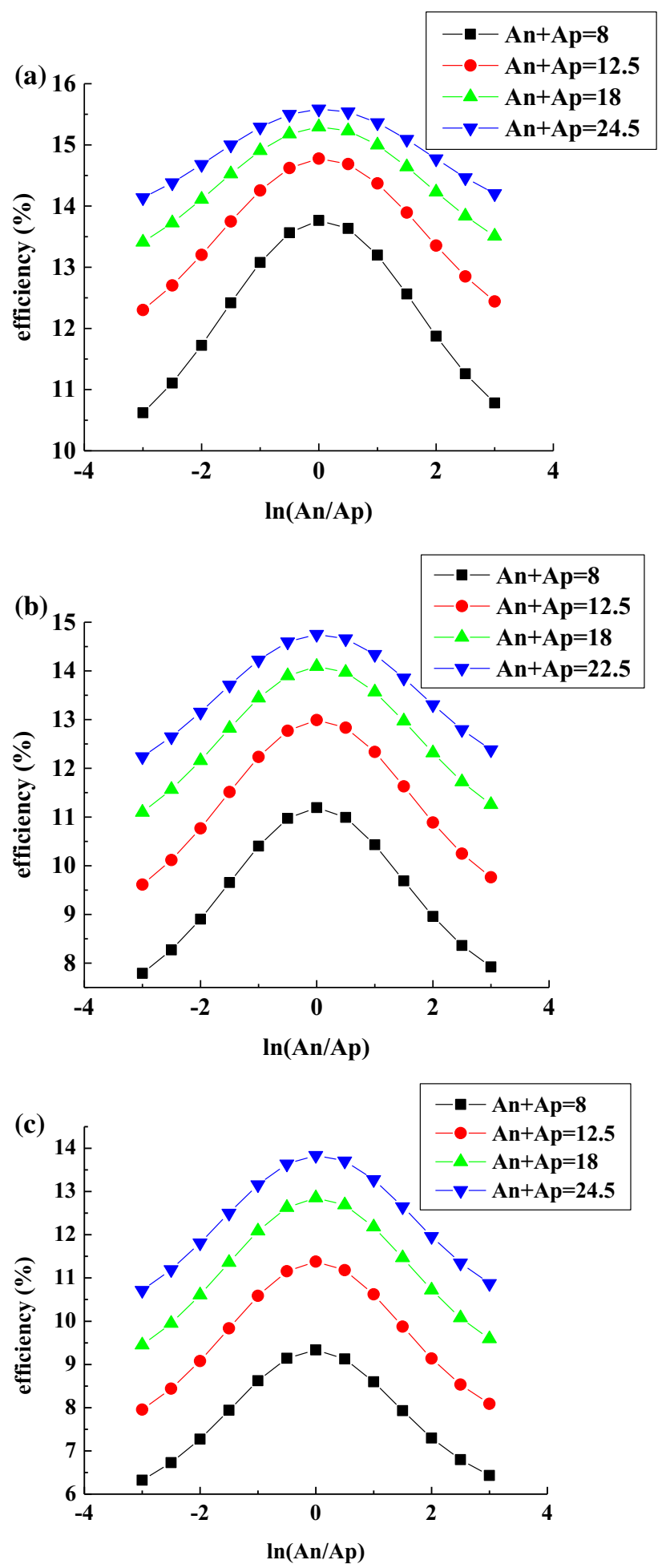

Fig. 7. Variation of the PV-TE efficiency with the area ratios between $n$-type and $p$-type using the PV Cell_2. The lengths of TE elements are (a) $5 \mathrm{~mm}$, (b) $10 \mathrm{~mm}$, and (c) $15 \mathrm{~mm}$.

thermoelectric element footprint areas have an advantage for PV-TE.

In addition, this study has also shown that the TEG element's length and area in the PV-TE have a 


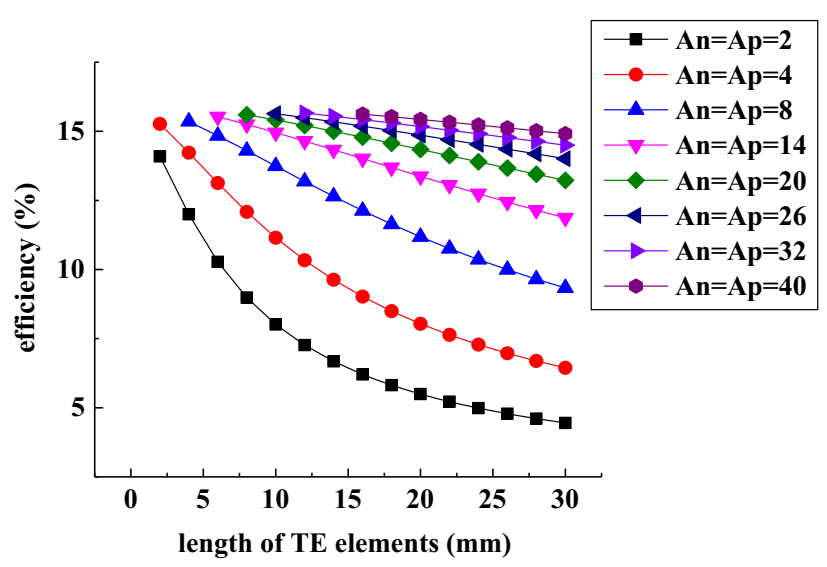

Fig. 8. Variation of the PV-TE efficiency with different length of TE elements based on Cell_2.

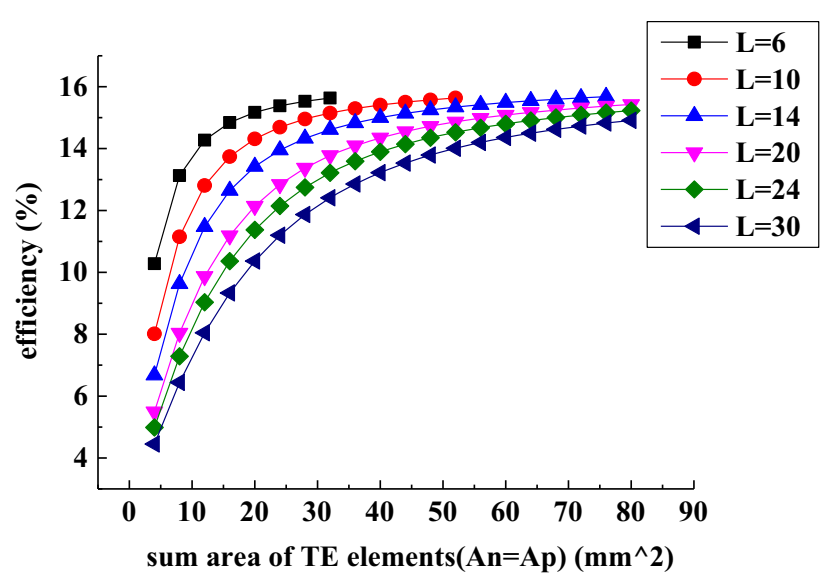

Fig. 9. Variation of the PV-TE efficiency with different footprint areas of TE elements based on Cell_2.

different relationship when different solar cells and different temperature coefficients are considered. In summary, the study has demonstrated the maximum PV-TE power generation optimal footprint area ratio and length.

\section{ACKNOWLEDGEMENTS}

The study was sponsored by the Project of EU Marie Curie International Incoming Fellowships Program (745614), National Science Foundation of China (Grant Nos. 51408578, 51611130195), Anhui Provincial Natural Science Foundation (1508085 QE96), National Key Research and Development Project (2016YFE0124800), Key Projects of Inter- national Cooperation of Chinese Academy of Sciences (211134KYSB20160005).

\section{OPEN ACCESS}

This article is distributed under the terms of the Creative Commons Attribution 4.0 International License (http://creativecommons.org/licenses/by/4.0/), which permits unrestricted use, distribution, and reproduction in any medium, provided you give appropriate credit to the original author(s) and the source, provide a link to the Creative Commons license, and indicate if changes were made.

\section{REFERENCES}

1. G. Li, J. Ji, G. Zhang, W. He, X. Chen, and H. Chen, Int. J. Energy Res. 40, 2117 (2016).

2. G. Li, G. Zhang, W. He, J. Ji, S. Lv, X. Chen, and H. Chen, Energy Convers. Manag. 112, 191 (2016).

3. G. Li, W. Feng, Y. Jin, X. Chen, and J. Ji, Heat Mass Transf. 53, 3249 (2017).

4. L.E. Bell, Science 321, 1457 (2008).

5. A.Z. Sahin and B.S. Yilbas, Energy Convers. Manag. 65, 26 (2013).

6. M. Borcuch, M. Musiał, S. Gumuła, K. Sztekler, and K. Wojciechowski, Appl. Therm. Eng. 127, 1355 (2017).

7. C.C. Wang, C.I. Hung, and W.H. Chen, Energy 39, 236 (2012).

8. B.S. Yilbas and H. Ali, Energy Convers. Manag. 100, 138 (2015).

9. J.Y. Jang and Y.C. Tsai, Appl. Therm. Eng. 51, 677 (2013).

10. Z.G. Shen, S.Y. Wu, and L. Xiao, Energy Convers. Manag. 89, 244 (2015).

11. R. Lamba and S.C. Kaushik, Energy Convers. Manag. 144, 388 (2017).

12. H. Ali, A.Z. Sahin, and B.S. Yilbas, Energy Convers. Manag. 78, 634 (2014).

13. E.D. Lavric, Energy 21, 133 (2010).

14. A. Rezania, L.A. Rosendahl, and H. Yin, J. Power Sources 255,151 (2014).

15. G. Li, X. Zhao, and J. Ji, Energy Convers. Manag. 126, 935 (2016).

16. Y.P. Zhou, M.J. Li, W.W. Yang, and Y.L. He, Appl. Energy 213, 169 (2018).

17. K. Teffah and Y. Zhang, Sol. Energy 157, 10 (2017).

18. H. Hashim, J.J. Bomphrey, and G. Min, Renew. Energy 87, 458 (2016).

19. Y. Wang, X. Zhang, L. Shen, N. Bao, C. Wan, N.H. Park, K. Koumoto, and A. Gupta, J. Power Sources 241, 255 (2013).

20. L.D. Landau and E.M. Lifshitz, Electrodynamics of continuous media, 2nd ed. (Oxford: Butterworth-Heinemann, 1984).

21. T. Seetawan, U. Seetawan, A. Ratchasin, S. Srichai, K. Singsoog, W. Namhongsa, C. Ruttanapun, and S. Siridejachai, Proc. Eng. 32, 1006 (2012).

22. A. Heghmanns, M. Beitelschmidt, S. Wilbrecht, K. Geradts, and G. Span, Mater. Today Proc. 2, 780 (2015).

23. G. Li, K. Zhou, Z. Song, X. Zhao, and J. Ji, Energy Convers. Manag. 161, 155 (2018).

24. G. Li, X. Chen, Y. Jin, and J. Ji, Energy Proc. 142, 730 (2017). 